\title{
O REFLEXO DO PROJETO NEOLIBERAL NAS POLÍTICAS PÚBLICAS EM TURISMO E TURISMO DE AVENTURA NO BRASIL
}

\author{
Recebido em: 01/12/2018
}

Aceito em: 19/08/2019

\author{
Rosane Camila de Godoi ${ }^{1}$ \\ Silvia Cristina Franco Amaral ${ }^{2}$ \\ Universidade estadual de Campinas (UNICAMP) \\ Campinas - SP - Brasil
}

\begin{abstract}
RESUMO: Este estudo é uma análise referente às políticas públicas no setor turístico sob a óptica do reflexo do projeto neoliberal no Brasil. Procurou-se na literatura entre os períodos de 1990 a 2018 estudos a respeito da influência neoliberal nas medidas e políticas públicas no país, buscando uma reflexão econômica-sociológica de como esse fenômeno poderia se relacionar com o desenvolvimento do turismo e turismo de aventura. Ademais, houve um conjunto de políticas públicas investigadas que por sua vez trouxeram um maior entendimento a respeito da expansão e desenvolvimento do turismo no Brasil a partir da década de 1990. Através dessa investigação, foi possível constatar uma aproximação relevante entre as políticas públicas para setor turístico e o desenvolvimento expressivo do turismo neste período, inclusive para o turismo de aventura, vertente impulsionada pelas políticas públicas de reflexo neoliberal.
\end{abstract}

PALAVRAS CHAVE: Políticas Públicas em Turismo. Turismo de Aventura. Neoliberalismo.

\section{THE NEOLIBERAL PROJECT AND ITS REFLECTION ON PUBLIC POLICIES ON TOURISM AND ADVENTURE TOURISM IN BRAZIL}

ABSTRACT: This study is an analysis of public policies in the tourism sector from the perspective of the reflex of the neoliberal project in Brazil. Between 1990 and 2018 , literature was searched for studies about the neoliberal influence on public policies and measures in the country, seeking an economic-sociological reflection on how this phenomenon could relate to the development of tourism and adventure tourism. In addition, there was a set of public policies investigated, which in turn brought a greater understanding of the expansion and development of tourism in Brazil since the 1990s. Through this investigation, it was possible to find a relevant approach between public policies for tourism sector and the expressive development of tourism in this period, including adventure tourism, a trend driven by public policies of neoliberal reflex.

\footnotetext{
${ }^{1}$ Bacharel em Educação Física pela UNICAMP.

${ }^{2}$ Docente da Faculdade de Educação Física e do Programa de Pós-graduação em Educação Física da UNICAMP. Líder do Grupo de Estudos e Pesquisa em Políticas Públicas e Lazer da UNICAMP.
} 
KEYWORDS: Public Policies in Tourism. Adventure Tourism. Neoliberalism.

\section{Introdução}

Esse trabalho pretende analisar na literatura a partir da década de 1990 estudos a respeito da influência neoliberal nas políticas públicas de turismo e turismo de aventura no Brasil. Nossa expectativa é de possibilitar uma reflexão econômicasociológica da influência neoliberal nas políticas públicas no setor turístico do Brasil, e como esse fenômeno pode se relacionar com o desenvolvimento do turismo.

Historicamente, o neoliberalismo surge logo após a II Guerra Mundial na Europa e na América do Norte, como uma reação teórico-política contra o Estado intervencionista e da política de Bem-Estar (Welfare State), que até então vigorava devido à reestruturação dos países pós-guerra. Seu texto de origem foi escrito em 1944, por Friedrich Hayek, intitulado "O Caminho da Servidão", que estabelece uma dura crítica aos mecanismos de limitação política e econômica por parte do Estado e acaba por ser a aplicação dos princípios do Liberalismo Clássico em uma sociedade capitalista pautada pela globalização e novos paradigmas (ANDERSON, 1995).

O termo Liberalismo Clássico provém dos séculos XVIII e XIX, e parte do pressuposto filosófico da liberdade individual defendida por John Locke, em meados de 1700, e depois por Adam Smith, em A Riqueza das Nações (1776), como uma consequência do direito natural do individualismo, que posteriormente passa para a esfera econômica e política (HOLANDA, 2001).

Em contraponto da então vigente norma econômica (no caso, o mercantilismo, que se resguardava ao acúmulo de metais preciosos, como ouro e prata, e na qual toda a atividade econômica era controlada pelo Estado) o liberalismo é apresentado como a teoria que defende a liberdade de comércio; direito à propriedade privada; 
desvinculação da economia do Estado e livre concorrência; além de ressaltar a divisão do trabalho em diferentes setores, pelo curso inevitável da modernização de ferramentas, maquinaria e variedade de trabalho e abertura de mercado com a liberação da exportação de moeda estrangeira e valorização dos demais produtos que não metais preciosos (SMITH, 2013).

Essa busca do lucro sem pensar no benefício social, de modo a deixar as disparidades econômicas tomarem seu curso natural sem a intervenção do Estado, é uma das grandes marcas que a filosofia do Liberalismo Clássico deixou posteriormente para o Liberalismo Econômico (HOLANDA, 2001). E não por acaso que a teoria de mercado de Adam Smith se torna o modelo teórico da ordem social liberal, no qual a economia passa a ser compreendida como a natureza de uma sociedade, que mesmo não descartando a tensão e conflitos inerentes da mesma, se apropria da pré-condição da garantia dos direitos de propriedade e da desigualdade produzida pela hierarquização dos homens (GANEM, 2000).

A respeito do liberalismo podemos notar que historicamente aparece atrelado à ascensão da burguesia e ao abismo que distancia o proletariado das condições vividas por essa classe social, dando margem para uma sequência de fatos influenciadores na decadência do liberalismo primitivo, dado principalmente a ausência da atuação do Estado nas relações econômicas e de trabalho (PIANHERI, 2014).

O abuso de poder e a extrema desigualdade social advindas da teoria liberal deram lugar a fome e a miséria em toda a Europa, durante o século XIX, que juntamente com doenças como a cólera e o tifo, efervesceram movimentos de trabalhadores no período pós-revolução industrial, acabando em inúmeras revoltas e rebeliões, dando espaço para o socialismo e comunismo. Após isso, a sociedade vem 
se organizando de distintas maneiras, seja pelo Estado de Direito, no qual a lei é soberana para todos, passando pelo Totalitarismo, definido pelo controle total dos líderes políticos sobre os direitos dos cidadãos, entre outros tipos de regimes político-econômicos (PIANHERI, 2014).

Os neoliberais da década de 1970 argumentavam que a desigualdade era um fator positivo, contando inclusive com a restauração da taxa "natural" de desemprego, e consequentemente de um contingente de trabalho reserva com força suficiente para desestruturar os sindicatos (ANDERSON, 1995).

No Brasil, de acordo com Bursztyn (2003), só é possível identificar a influência da política econômica neoliberal no desenvolvimento da atividade turística no Brasil se nos atentarmos para o surgimento das primeiras medidas para o setor (BURSZTYN, 2003).

Foi possível, através de uma análise bibliográfica, fomentar um levantamento histórico do neoliberalismo no Brasil, e de como esse movimento influenciou as políticas públicas, em especial no turismo e turismo de aventura. Mas, o que explica essa ressurgência e nova dissipação de um novo liberalismo em um mundo capitalista moderno? Anderson (1995), argumenta:

[...] a queda do comunismo na Europa Oriental e na União Soviética, de 89 a 91, exatamente no momento em que os limites do neoliberalismo no próprio Ocidente tornavam-se cada vez mais óbvios. Pois, a vitória do Ocidente na guerra fria, com o colapso de seu adversário comunista, não foi o triunfo de qualquer capitalismo, mas o do tipo específico liderado e simbolizado por Reagan e Thatcher nos anos 80 (ANDERSON, 1995).

Inicialmente, na América Latina se fez presente uma variante neoliberal em países como Chile e Bolívia até o final dos anos 1980. Pinochet ficou conhecido por ter um governo com alta taxa de desemprego, forte repressão sindical e efetivação de uma série de privatizações no Chile (ANDERSON, 1995). 
Em seguida México, em 1988, Argentina sob o segundo mandato de Carlos Andrés Perez, em 1989, depois Venezuela e Peru, todos instituídos por iniciativa governamental, como se daria mais adiante no Brasil, com a hiperinflação durante a presidência de Sarney (ANDERSON, 1995).

Porém, o neoliberalismo como doutrina não pôde ser aplicado em toda sua extensão de ideias, o que foi implantado nos países latino-americanos foi um projeto neoliberal, como explica Filgueiras (2006):

Preliminarmente, se faz necessário diferenciar, conceitualmente, neoliberalismo, projeto neoliberal e modelo econômico neoliberal periférico. O primeiro diz respeito à doutrina político-econômica mais geral, formulada, logo após a Segunda Guerra Mundial, por Hayek e Friedman, entre outros - a partir da crítica ao Estado de Bem-Estar Social e ao socialismo e através de uma atualização regressiva do liberalismo (Anderson, 1995). O segundo se refere à forma como, concretamente, o neoliberalismo se expressou num programa político-econômico específico no Brasil, como resultado das disputas entre as distintas frações de classes da burguesia e entre estas e as classes trabalhadoras. Por fim, o modelo econômico neoliberal periférico é resultado da forma como o projeto neoliberal se configurou, a partir da estrutura econômica anterior do país, e que é diferente das dos demais países da América Latina, embora todos eles tenham em comum o caráter periférico e, portanto, subordinado ao imperialismo. Em suma, o neoliberalismo é uma doutrina geral, mas o projeto neoliberal e o modelo econômico a ele associado, são mais ou menos diferenciados, de país para país, de acordo com as suas respectivas formações econômico-sociais anteriores (FILGUEIRAS, 2006).

Sendo assim, institui-se no Brasil um projeto neoliberal que se definiu em resposta à crise do Modelo de Substituição de Importações (MSI) (FILGUEIRAS, 2006), na qual detinha o controle seletivo das importações e que posteriormente deu lugar à outros modelos como mecanismos para dar continuidade ao progresso desenvolvimentista, dado o aumento das exportações (SILVA, 2003). Defendia também a capacidade produtiva dos setores de insumos básicos, mineração, petroquímica, energia e telecomunicações fechando as estatais deficitárias e renegociando a dívida externa, desse modo, essa nova onda liberal já havia forte 
influência nos países da América Latina, incluindo o Brasil após os anos de 1990. (FILGUEIRAS, 2006).

A nova classe emergente (os novos ricos) tendeu a rejeitar políticas parecidas com um Estado de Bem-Estar Social, pois não se beneficiariam diretamente com tais medidas, principalmente no que se refere à alta classe média, pois, quanto mais igualitários os direitos sociais, assim como o usufruto dos serviços públicos, mais esse estrato social padece com declínio social e perda de renda, diretamente relacionada aos impostos que o Estado faria incidir sobre as abastadas famílias. Pode-se afirmar ainda, que o projeto neoliberal e seu discurso doutrinário se difundiram conseguindo apoio e concordância em nossa sociedade a favor de uma onda de privatização e principalmente porque parte dos trabalhadores não consegue ver além desse modelo neoliberal, admitindo-o passivamente, acreditando e defendendo que as reformas neoliberais são uma alternativa de melhoria social. (BOITO, 2006).Esse encadeamento de medidas deu corpo à evolução do modelo econômico neoliberal periférico no Brasil, que pode ser divido em três fases desde o início dos anos 1990: durante o governo Collor e a ruptura com o MSI, caracterizando a inserção das medidas de natureza neoliberal; um segundo momento de assentamento e expansão, no primeiro mandato de Fernando Henrique Cardoso - FHC; e finalmente uma etapa de adaptação e ajuste desse novo modelo neoliberal, no qual passa pelo segundo governo FHC, governo Lula e se faz presente até os dias atuais (FILGUEIRAS, 2006).

Em relação às medidas adotadas, Muller e Surel (1998), definem como Política Pública um conjunto de produtos e medidas concretas, podendo ser: financeiras, reguladoras ou materiais, pelo qual exigem mecanismos de ação pública, construindo um quadro normativo de ações planejadas e executadas de forma coletiva 
pelos diversos setores da administração pública, com participação das instituições representativas da sociedade (MULLER \& SUREL, 1998).

No Brasil, o estabelecimento de políticas públicas de cunho neoliberal no setor turístico foi concomitante ao surgimento do Turismo de Aventura (TA). Por sua vez, o TA é a variável comercial dos Esportes de Aventura, até então não regulamentados ou padronizados, sua primeira definição oficial surgiu em Caeté, Minas Gerais, na oficina para elaboração do Plano Nacional de Desenvolvimento Sustentável do Turismo de Aventura, em abril de 2001 (OLIVEIRA \& COVOLAN, 2008).

Podemos caracterizar o turismo de aventura como sendo uma vivência que contém risco de variáveis controladas, podendo ser explorado nos mais diversos tipos de ambientes, sobretudo em meio a natureza (CÁSSARO, 2011).

Atualmente, é normatizado pela NBR 15500/2007 da Associação Brasileira de Normas Técnicas (ABNT) e definido por atividades recreativas comercialmente adaptadas das atividades de aventura, na qual seus riscos são minimizados e mais controlados (ALVES et al, 2016).

Substancialmente, associa-se também a atividade turística ao caráter da aventura com seu traço mais significativo: sua conexão com a natureza através de um espírito inovador, através da adoção de procedimentos e equipamentos específicos que possam garantir a segurança pessoal e a preservação ao patrimônio ambiental e sociocultural (ABETA, 2009).

Dito isto, investigaremos se há uma conexão entre a influência neoliberal no Brasil a partir dos anos de 1990 e as políticas públicas de turismo, focando no desenvolvimento expressivo do ecoturismo e turismo de aventura como um produto de alto potencial econômico brasileiro. 
Frente ao exposto fomos estimuladas a realizar uma análise da literatura em português sobre o tema no período de 1990 a 2018. Procuramos verificar como os autores analisaram a influência das políticas neoliberais no turismo no Brasil.

\section{Metodologia}

Para fomentar o presente estudo foi realizada uma busca nas bases de dados relativos à área das humanidades, turismo e educação física.

Houve uma pré-seleção nos quais as palavras chaves eram: políticas públicas e turismo no Brasil; neoliberalismo e turismo de aventura; neoliberalismo e turismo no Brasil, políticas públicas e influência neoliberal; e lazer e turismo de aventura no Brasil, que somaram 68 textos. A partir dos resumos desses artigos, utilizou-se 31 estudos, pois se encaixaram nos critérios definidos para análise em questão.

O passo seguinte foi a leitura e síntese do material. Após um período de aproximação e coleta de informações pertinentes ao objetivo desse estudo, foi possível montar um panorama geral do surgimentos das políticas públicas em turismo no Brasil, e a partir desse ponto, traçar uma análise do desenvolvimento do turismo de aventura e esportes relacionados.

A partir dos conhecimentos da metodologia da Análise de Conteúdo, buscouse organizar esta pesquisa a fim de enriquecer, com dados organizados e representativos, o tema em questão.

Este estudo constitui uma revisão bibliográfica de caráter analítico a respeito das políticas públicas em turismo e turismo de aventura a partir do reflexo do projeto neoliberal no Brasil.

A coleta de dados foi realizada no período de 25 de Maio de 2018 a 15 de abril de 2019. As bases de dados utilizadas para a pesquisa foram: Scientific Eletrônic 
Library Online (SCIELO); Google Acadêmico, National Library of Medicine (PUBMED); Caderno Virtual de Turismo; e-books Google; Academia.edu; Acervus UNICAMP; Repositório Institucional USP e UNB; Biblioteca Virtual CLACSO; Repositório Digital Fatu e FGV; Biblioteca Virtual UFRJ; Revista Conexões; Revista Motriz; Site do Ministério do Turismo e da ABETA.

Foi definido como critério de inclusão: artigos publicados a partir de 1990, pois levantamentos iniciais identificaram que no período anterior a esse não correspondiam a uma possível interferência de uma política neoliberal. Portanto, optou-se pelo período entre 1990 e 2018 por acreditar que esse recorte temporal seria capaz de cobrir as principais publicações relacionadas as políticas públicas no setor, e como elas teriam afetado o turismo e TA no Brasil.

Após a seleção dos artigos conforme os critérios de inclusão previamente definidos, foram seguidos, nessa ordem, os seguintes passos: leitura exploratória; leitura seletiva e escolha do material que se adequam aos objetivos e tema deste estudo; leitura analítica e análise dos textos, finalizando com a realização de leitura interpretativa e redação. Após estas etapas, constituiu-se um corpus do estudo agrupando os temas mais abordados nas seguintes categorias: Políticas Públicas em Turismo, Neoliberalismo no Brasil e Medidas/Políticas Públicas em Turismo de Aventura.

\section{Resultados e Discussão}

\section{A Influência Neoliberal e o Desenvolvimento do Turismo no Brasil}

O livre comércio, o fortalecimento das relações produtivas, liquidez de capital monetário e aumento do fluxo de troca de moeda e mercadorias entre países são 
fatores que marcam a personificação da influência neoliberal capitalista no Brasil, acompanhando o movimento global (GUTIERREZ, 2005).

Ademais, dentre as reformas que caracterizaram o projeto neoliberal no Brasil podemos destacar a incorporação de um conjunto de medidas que visavam atrair capital externo através da abertura do mercado nacional, a disciplina fiscal para controle dos déficits do Estado, a reforma tributária e claro, uma onda de privatizações (TELES et al, 2016).

A reestruturação produtiva advinda dessas novas medidas levou à informalidade, desemprego estrutural, terceirização e enfraquecimento dos sindicatos, assim como expandiu o setor terciário (comércios, entretenimento, prestação de serviços, lazer e turismo) em detrimento do setor secundário (indústria) (GUTIERREZ, 2005). Esse novo período, marcado pela diminuição da interferência do Estado nos distintos espectros da vida da sociedade reafirmou o direito de propriedade e os direitos do consumidor, que se sobrepuseram aos direitos sociais dos cidadãos, tornando o lazer e turismo acessível apenas para uma parcela da população (BORGES \& AREIAS, 2011).

A partir dos anos 1990, o modelo de Estado Intervencionista cede lugar para um conceito de intervenção mínima em questões sociais e uma intersetorialidade das ações no desenvolvimento de Políticas Públicas voltadas para o lazer e turismo. Entre elas, o governo diminui a taxação sobre o capital e impostos, ao mesmo tempo em que afunila consideravelmente os recursos destinados às políticas sociais (BORGES \& AREIAS, 2011).

É possível relacionar a expansão do turismo no Brasil com o desenvolvimento do TA à medida que são criadas e aplicadas políticas públicas de cunho neoliberal nesse setor. O TA é entendido como uma atividade relacionada diretamente ao 
Ecoturismo, porém, atualmente possui características mercadológicas e de estrutura próprias decorrentes da necessidade de uma experiência turística na natureza, com participação controlada dos riscos ao turista (BRASIL, 2006). Segundo o documento de Segmentação do Turismo: Marcos Conceituais, o TA "compreende os movimentos turísticos decorrentes da prática de atividades de aventura de caráter recreativo e não competitivo" (2006, pp. 39).

Abaixo, podemos acompanhar as principais políticas públicas e medidas adotadas durante o governo Collor, um marco da influência do projeto neoliberal na economia e na política do país, e como cada uma delas afetou o setor. O quadro em questão foi construído a partir das consultas literárias contidas nas referências bibliográficas:

Quadro 1: Principais políticas públicas em Turismo durante o governo Collor.

\begin{tabular}{|c|c|c|}
\hline Ano & Política pública ou marco no setor & Consequência \\
\hline 1990 & Plano Nacional de Turismo, decreto 448/92 & $\begin{array}{l}\text { EMBRATUR ganha o título de Instituto } \\
\text { Brasileiro de Turismo }\end{array}$ \\
\hline 1990 & Cambio de papéis da dívida externa & Estratégia de alavancamento econômico \\
\hline 1991 & Lei n. 8.181/91 - Política Nacional de Turismo & $\begin{array}{l}\text { Conjunto de diretrizes e normas integradas para o } \\
\text { desenvolvimento do setor turístico }\end{array}$ \\
\hline 1991 & $\begin{array}{l}\text { Prodetur-Programa de Ação para o } \\
\text { Desenvolvimento do Turismo }\end{array}$ & Incentivo ao desenvolvimento do turismo regional \\
\hline 1991 & $\begin{array}{l}\text { Criação de políticas públicas tendendo a um } \\
\text { favorecimento de empresas privadas }\end{array}$ & $\begin{array}{l}\text { Também fica mais evidente o termo } \\
\text { “desenvolvimento sustentável” em documentos } \\
\text { oficiais: novo nicho turístico }\end{array}$ \\
\hline 1992 & Eco-92 (Evento de ecologia e ecoturismo) & $\begin{array}{l}\text { Chama a atenção para o novo nicho turístico: o } \\
\text { Ecoturismo }\end{array}$ \\
\hline 1992 & $\begin{array}{l}\text { Lei n. 8.623/1993, regulamentada pelo Decreto n. } \\
946 / 1993\end{array}$ & $\begin{array}{l}\text { Capacitação e regulamentação dos guias de } \\
\text { turismo }\end{array}$ \\
\hline 1992 & PlanTur - Plano Nacional de Turismo & $\begin{array}{l}\text { Promove a parceria entre os setores público e } \\
\text { privado }\end{array}$ \\
\hline 1992 & $\begin{array}{l}\text { Prodetur/NE-Programa de Desenvolvimento do } \\
\text { Turismo no Nordeste }\end{array}$ & $\begin{array}{l}\text { Destinado à implantação de projetos de } \\
\text { infraestrutura básica no Nordeste }\end{array}$ \\
\hline
\end{tabular}

Fonte: Elaboração própria

Diante desse cenário, podemos apontar o exemplo do Nordeste Brasileiro, vendido como o "Novo Caribe", que lança mão da Política Nacional de Turismo para se reestruturar, com abertura comercial para atrair o capital estrangeiro na construção 
de hotéis e resorts, típicos de grandes centros turísticos internacionais (BURSZTYN, 2003).

Ademais, é durante o governo Collor que intenção de cambiar papéis da dívida externa brasileira por investimentos turísticos no país fica evidente, e a Política Nacional de Turismo, apontada como uma política pública de forte tendência neoliberal, determina novos objetivos como democratizar o acesso ao turismo nacional, além de aumentar os fluxos turísticos, a taxa de permanência e o gasto médio do turista estrangeiro no país. Tudo isso devido à profunda crise instaurada no país, no qual a atividade turística foi apontada como uma possível estratégia de alavancamento econômico apontada por órgãos internacionais como o Fundo Monetário Internacional (FMI), Banco Interamericano de Desenvolvimento (BID) e Banco Internacional para Reconstrução e Desenvolvimento (BIRD) (BURSZTYN, 2003).

A Política Nacional de Turismo mais relevante foi instituída no ano de 1991, e mesmo historicamente a intencionalidade nas políticas públicas de turismo estar atrelada ao desenvolvimento econômico da atividade, tendendo a um favorecimento de empresas privadas, o Governo Federal passa então a adotar um discurso utilizando o termo "desenvolvimento sustentável" em documentos oficiais, chamando mais atenção para o setor (CANDIOTTO \& BONETTI, 2015).

Por sua vez, a Lei 8.181/91 - Política Nacional de Turismo, além de reestruturar a EMBRATUR de modo que passa a ser coordenadora e indutora de atividades, ao contrário da posição que anteriormente exercia de ser legisladora e executora do turismo (tornando-a uma autarquia especial), integrou normas e diretrizes para o desenvolvimentos do setor, essa é citada como a lei mais completa e 
detalhada da história das políticas federais para o turismo (CANDIOTTO \& BONETTI, 2015).

Em julho de 1992, a EMBRATUR lança o Plano Nacional de Turismo (Plantur) promovendo a parceria entre os setores privado e público (BURSZTYN, 2003). O Plano Nacional de Turismo (Plantur) propôs uma mudança da concepção de planejamento do turismo dentre os anos de 1992 a 1994, seu objetivo era a utilização dos recursos públicos para um bem-estar social através do desenvolvimento regional do turismo, orientando as políticas de governo e ordenando as ações do setor público, porém, em razão da instabilidade política em vigor naquele tempo, não teve forças para se projetar (CARVALHO, 2016).

Concomitantemente os governos estaduais do nordeste formularam o Programa de Desenvolvimento do Turismo no Nordeste (Prodetur-NE), uma reprodução fiel das diretrizes do plano federal com recursos destinados à implementação de projetos de infraestrutura básica como energia elétrica, rodovias, água e saneamento para a sustentação do turismo, criando um ambiente propício para o capital de grandes grupos transnacionais interessados em desenvolver polos turísticos no modelo mexicano (BURSZTYN, 2003).

O Prodetur/NE - Programa de Desenvolvimento do Turismo no Nordeste, se fortaleceu à medida que o governo federal passa a autorizar a contratação de operação de crédito externo pelo Banco do Nordeste do Brasil S.A. (BNB) com o Banco Interamericano de Desenvolvimento (BID) (CARVALHO, 2016), o que indica um forte aporte externo para a manutenção do turismo no Brasil.

É possível identificar as características neoliberais em tais políticas, pois, a abertura a um capital externo, conjuntamente com a parceria público-privada 
fortaleceu a iniciativa de grandes empresas particulares no fomento do setor turístico da época, características inerentes do projeto neoliberal.

Assim como abordado anteriormente, abaixo podemos conferir as principais iniciativas que ocorreram posteriormente, durante o período Itamar Franco.

\section{Quadro 2: Principais políticas públicas em Turismo durante o governo Itamar} Franco.

\begin{tabular}{l|l|l}
\hline Ano & Política pública ou marco & Consequência \\
\hline 1993 & $\begin{array}{l}1^{\circ} \text { Curso de Formação de Guias de Turismo de } \\
\text { Atrativos Naturais }\end{array}$ & $\begin{array}{l}\text { Primeiras normas de práticas de visitação, surgidas em } \\
\text { Bonito -MT }\end{array}$ \\
\hline 1993 & Brotas cria o Conselho Municipal de Turismo & $\begin{array}{l}\text { Começa a popularização de turismo de aventura, como } \\
\text { boia cross e rafting }\end{array}$ \\
\hline 1994 & $\begin{array}{l}\text { Programas de Ecoturismo: Parques do Brasil e e } \\
\text { Proecotur Amazônia }\end{array}$ & $\begin{array}{l}\text { Viabilizar o desenvolvimento do ecoturismo e turismo } \\
\text { sutentável na região da Amazônia e demais Parques } \\
\text { Nacionais }\end{array}$ \\
\hline 1994 & $\begin{array}{l}\text { PNMT-Programa Nacional de } \\
\text { Municipalização do Turismo }\end{array}$ & Modelo de gestão turística em escala municipal \\
\hline
\end{tabular}

Fonte: Elaboração própria

As primeiras medidas de regulamentação do setor começam a ser tomadas, como a especialização da mão de obra e a formação de Conselhos Municipais, como Brotas e posteriormente Socorro, ambas as cidades do interior paulista, assim como a expansão de programas de Ecoturismo, que ganharam grande visibilidade após o evento Eco-92, no Rio de Janeiro.

A partir do PNMT - Programa Nacional de Municipalização do Turismo, esperava-se que os municípios se envolvessem mais no programa de modo a formar regiões turísticas. Atingindo 1.529 municípios, foi considerado o programa de maior impacto na política setorial do turismo já proposto até então, o PNMT associado a política de ecoturismo, consegue então contemplar todos os estados do país, como região Centro-Oeste, que até então não havia sido beneficiado diretamente, pois os produtos oferecidos até então estavam sempre relacionados a marca "sol e praia", típica do turismo brasileiro (CARVALHO, 2016).

Durante o período FHC, o governo federal visou desenvolver e fortalecer alguns fatores do Plano Nacional de Turismo (Plantur), tais como: redução das 
desigualdades regionais, geração e distribuição de renda (através da regionalização e interiorização da atividade turística), geração de renda, inovação nas interações e relações da cadeia produtiva do turismo e equilíbrio econômico "através da geração de divisas 'limpas' tais como aquelas originadas pelas exportações e pelo turismo receptivo" (BRASIL \& PLANELLO).

Podemos acompanhar como se deu o processo de desenvolvimento do turismo entre os anos de 1996 a 2002, durante o mandato de Fernando Henrique Cardoso a partir do quadro a seguir:

Quadro 3: Principais políticas públicas em Turismo durante o governo FHC.

\begin{tabular}{|c|c|c|}
\hline Ano & Política pública ou marco & Consequência \\
\hline 1996 & Política Nacional de Turismo & $\begin{array}{l}\text { Promover e incrementar o turismo como parte do } \\
\text { desenvolvimento socioeconômico }\end{array}$ \\
\hline 2001 & $\begin{array}{l}\text { Medida Provisória } n^{\circ} 2216-37 \text { de } 31 \text { de agosto } \\
\text { de } 2001\end{array}$ & É criado o Conselho Nacional de Turismo (CNT) \\
\hline 2002 & $\begin{array}{l}\text { Plano para o Desenvolvimento do Turismo de } \\
\text { Aventura no Estado de São Paulo }\end{array}$ & $\begin{array}{l}\text { Identificação dos limites e potenciais do turismo de } \\
\text { aventura no estado de SP }\end{array}$ \\
\hline
\end{tabular}

Fonte: Elaboração própria

Um dos mais importantes acontecimentos durante o mandato $\mathrm{FHC}$, foi a criação do Conselho Nacional de Turismo (CNT) através da Medida Provisória $n^{\circ}$ 2216-37 de 31 de Agosto de 2001, sendo um órgão colegiado com 70 conselheiros de instituições públicas e privadas do setor, com o objetivo de auxiliar, formular, discutir e planejar propostas referentes à Política Nacional de Turismo, sob a função "de assessorar o Ministro de Estado do Turismo na formulação e aplicação da Política Nacional de Turismo e dos planos, programas, projetos e atividades derivadas" (CANDIOTTO \& BONETTI, 2015).

Devido a expansão do turismo, e a popularização do TA, a Secretaria Estadual de São Paulo, a prefeitura e o Conselho Municipal de Turismo de Socorro juntamente com a EMBRATUR, lançam em 2002 o Plano para o Desenvolvimento do Turismo de Aventura no Estado de São Paulo, que mapeou as limitações e possibilidades do então setor emergente (ABETA, 2009). 
O governo Fernando Henrique também deu grande importância para os acordos bilaterais, em que num primeiro momento visavam o estabelecimento de cooperação entre o Brasil e outros países, e a partir de 2001 há uma tendência em diminuir os entraves burocráticos na demanda turística, como a isenção de vistos para a entrada em países que possuíam acordos de fomento de turismo, como a Turquia e Coreia do Sul (TELES et al, 2016).

Teles e colaboradores (2016) também apontam para um terceiro momento no governo FHC, de perfil mais comercial, que previa investimentos no setor turístico, mas, que devido a influência do neoliberalismo, culminaram em um aumento da vulnerabilidade externa do Brasil, que ficou evidente com as crises que o país foi atingido em 1995, 1997, 1998 e 2001, respectivamente crises: da dívida mexicana, crise asiática, crise russa e crise argentina.

No período Lula, de 2003 a 2010, adotou-se um discurso de geração de empregos e inclusão social através do ideário desenvolvimentista do turismo (LAZARINI \& BARRETO, 2014). Segundo estudo de Teles e colaboradores, a atividade turística passa a ganhar maior importância, recebendo aporte de recursos e estudos específicos no segmento de planejamento e atuação do Ministério do Turismo numa política de qualificação da mão de obra e integração dos potenciais turísticos, sendo essas condições que acabaram por fortalecer o ramo de viagens e negócios; (TELES et al., 2016). Principais acontecimentos: 
Quadro 4: Principais políticas públicas em Turismo durante o governo Lula.

\begin{tabular}{|c|c|c|}
\hline Ano & Política pública ou marco & Consequência \\
\hline 2003 & $\begin{array}{l}\text { Ciclo de Seminários Regionais de Turismo de } \\
\text { Aventura no Estado de São Paulo }\end{array}$ & Debates sobre turismo de aventura e segurança \\
\hline 2003 & $\begin{array}{l}\text { Criação de } 24 \text { normas técnicas para as atividades de } \\
\text { turismo de aventura }\end{array}$ & $\begin{array}{l}\text { Diretrizes necessárias para o desenvolvimento } \\
\text { das políticas em TA }\end{array}$ \\
\hline 2003 & Criação do Ministério do Turismo & $\begin{array}{l}\text { Orientar as ações necessárias para consolidar o } \\
\text { desenvolvimento do setor turístico }\end{array}$ \\
\hline $\begin{array}{l}2003- \\
2010\end{array}$ & $\begin{array}{l}\text { Política de qualificação da mão de obra e integração } \\
\text { dos potenciais turísticos }\end{array}$ & A atividade turística ganha maior importância \\
\hline $\begin{array}{c}2007- \\
2010 \\
\end{array}$ & Plano Nacional de Turismo & $\begin{array}{l}\text { Parcerias entre o setor público e privado e } \\
\text { descentralização das ações no turismo }\end{array}$ \\
\hline 2007 & PRT-Programa de Regionalização do Turismo & $\begin{array}{l}\text { Organização do espaço geográfico em regiões } \\
\text { para fins de gestão e planejamento }\end{array}$ \\
\hline 2005 & Programa Aventura Segura da ABETA & $\begin{array}{l}\text { Tem como objetivo uma operação segura e } \\
\text { responsável dentro do segmento }\end{array}$ \\
\hline 2008 & Lei do Turismo $\mathrm{n}^{\mathrm{o}} 11.771 / 2008$ & $\begin{array}{l}\text { Define as atribuições do Governo Federal } \\
\text { dentro do setor turístico }\end{array}$ \\
\hline
\end{tabular}

Fonte: Elaboração própria

O governo Lula apresenta também diretrizes de cunho neoliberal, pois tem como objetivo aumentar a competitividade internacional do turismo no Brasil, como um vetor de inclusão social e desenvolvimento, como apontam Candiotto e Bonetti (2015):

Mesmo com toda uma trajetória de contestação ao domínio do mercado, o governo Lula adotou fundamentos neoliberais em seu Plano Nacional de Turismo, primando pelo viés econômico e pelo aumento da competitividade do país no mercado internacional, apesar de um discurso de benefícios coletivos a partir do turismo. Assim, da mesma forma que no governo FHC, o governo Lula manteve um cunho neoliberal para o tratamento do turismo no Brasil, destacando as parcerias entre o setor público e privado e a ideia de descentralização das ações no turismo, através do discurso de incentivo à participação das diversas instituições envolvidas, e também da sociedade civil (CANDIOTTO \& BONETTI, 2015).

A década de 1990 foi de grande relevância para o setor turístico, porém, a criação do Ministério do Turismo (Mtur), em 2003, foi um marco regulatório para o planejamento e constituição de uma política específica para o ramo, no qual a Embratur transferiu suas funções e passou a dar apoio logístico à execução das atividades do Mtur. O PNT - Plano Nacional de Turismo 2003 a 2007, concomitantemente deu suporte à política do setor pelo Decreto ${ }^{\circ} 4.898 / 2003$, Lula 
afirmava que havia a necessidade de criar empregos e diminuir as desigualdades regionais através de um turismo responsável (CARVALHO, 2016).

Em 2004 houve a implantação do Programa de Regionalização do Turismo (PRT), que tinha como objetivo a organização de diversas regiões turísticas, ou seja, um espaço geográfico para fins de gestão, planejamento e comercialização integrada de um produto turístico. O PRT teve como princípios básicos a sustentabilidade, participação e integração de municípios e a descentralização da demanda turística. Posteriormente, em 2007, foi reforçada pelo Plano Nacional de Turismo, que buscou dar continuidade e profundidade ao programa (CANDIOTTO \& BONETTI, 2015).

Também em 2007, o Mtur lançou os Macroprogramas, desdobramentos temáticos escolhidos para a formulação e implementação da nova Política Nacional de Turismo, que manteve a base para uma gestão política descentralizada e participativa (SILVA et al., 2013), porém, com algumas alterações. Esse novo PNT, seguiu os passos do anterior, mas, com enfoque principalmente na inclusão social no processo turístico, assim como o fortalecimento do turismo interno como fator de desenvolvimento e crescimento regional a medida que se apoiou e se integrou às vertentes do PAC (Plano de Aceleração do Crescimento) (GALDINO \& COSTA, 2011).

Em 2008 houve a criação da Lei n ${ }^{\circ} 11.771$, conhecida como a Lei do Turismo, que dispõe sobre a PNT e passa definir as atribuições do Governo Federal dentro do setor turístico, como o seu planejamento, desenvolvimento entre outras providências e revoga as leis anteriores. Essa lei traz um marco regulatório e torna-se referência na gestão pública, definindo uma gestão ética e delineando as atribuições do Governo Federal no estímulo, planejamento e desenvolvimento do setor turístico, dispondo 
sobre a Política Nacional de Turismo e delegando responsabilidades ao poder público e cadeia produtiva do setor (CANDIOTTO \& BONETTI, 2015).

Em relação ao cenário político subsequente e apesar de não implementar oficialmente uma política pública até o início de 2013, o governo Dilma Roussef, que se iniciou em 2011, manteve as ações advindas da administração anterior, inclusive as advindas do Plano de Aceleração do Crescimento (PAC), e priorizou a captação de recursos e ampliação de infraestrutura para sediar os megaeventos: Copa do Mundo de Futebol 2014 e Jogos Olímpicos 2016 (LAZARINI \& BARRETO, 2014).

Quadro 5: Principais políticas públicas em Turismo durante o governo Dilma.

\begin{tabular}{|c|c|c|}
\hline Ano & Política pública ou medida proposta & Consequência \\
\hline $\begin{array}{l}2011- \\
2016 \\
\end{array}$ & PAC- Plano de Aceleração do Crescimento & $\begin{array}{l}\text { Associar infraestrutura urbana ao } \\
\text { aperfeiçoamento de recursos humanos }\end{array}$ \\
\hline $\begin{array}{l}2011- \\
2016 \\
\end{array}$ & Plano Cores do Brasil & Plano de marketing nacional \\
\hline $\begin{array}{l}2011- \\
2016 \\
\end{array}$ & Plano Aquarela & Plano de marketing internacional \\
\hline 2011 & $\begin{array}{l}\text { Captação de recursos e ampliação de infraestrutura } \\
\text { para sediar os megaeventos }\end{array}$ & $\begin{array}{l}\text { Gestão pública com parcerias público-privadas } \\
\text { direcionado à infraestrutura das cidades-sede }\end{array}$ \\
\hline $\begin{array}{l}2011- \\
2013\end{array}$ & $\begin{array}{l}\text { PNT 2013-2016, principal documento referencial do } \\
\text { turismo }\end{array}$ & $\begin{array}{l}\text { Legado de mobilidade urbana e infraestrutura } \\
\text { aeroportuária }\end{array}$ \\
\hline
\end{tabular}

Como uma maneira de atender às expectativas diante o cenário internacional, o Ministério do Turismo lançou o Plano Aquarela, com previsões para 2020, que por sua vez visa aprimorar, envolver, aproveitar e promover o turismo brasileiro, em especial sobre grandes eventos como a Copa do Mundo de 2014 e os Jogos Olímpicos de 2016, maximizando resultados, otimizando a apresentação nacional e atualizando a imagem do país pela internet e canais de comunicação, de modo a melhor atender a promoção do turismo em um cenário internacional (GALDINO \& COSTA, 2011).

Em vista do avanço significativo do Turismo Receptivo, dado pelo aumento da demanda do turismo emissivo dos Megaeventos Esportivos, e com o suporte do documento PNT 2013-2016, principal documento referencial do turismo, houve um destaque voltado a esse tipo de turismo, deixando um legado de mobilidade urbana e 
infraestrutura aeroportuária, fatores que deixaram o Brasil um destino turístico competitivo no mercado doméstico e também internacional (CARVALHO, 2014b).

É portanto, possível identificar uma economia neoliberal no desenvolvimento da atividade turística no Brasil, se analisarmos as primeiras políticas para o setor implementados nas últimas décadas. Desde a criação da Empresa Brasileira de Turismo (EMBRATUR), em 1966, havia pouco planejamento da atividade turística, foi a partir dos anos 1990, que a EMBRATUR ganha o título de Instituto Brasileiro de Turismo e assume a Política Nacional de Turismo, passando a desempenhar papel fundamental na formulação de políticas públicas para o setor (BURSZTYN, 2003).

\section{O Projeto Neoliberal nas Políticas Públicas de Turismo de Aventura no Brasil}

Somente a partir dos anos 1990 que o Ecoturismo e Turismo de Aventura no Brasil começam a se destacar como uma atividade viável dentro do segmento turístico, especificamente após o governo Collor, através da criação e propagação, ainda que não formalmente, das empresas do ramo (ABETA, 2009).

Foi a partir daí que o público consumidor se diversificou, passando a ser formado por famílias de classe média, grupos de jovens e estrangeiros, e foi justamente na década de 1990 que as primeiras políticas de turismo organizado surgem no país, referencialmente em Brotas (SP) e Bonito (MT) (ABETA, 2009).

Algumas políticas públicas criadas nesse formato neoliberal foram: os Programas de Ecoturismo, principalmente o Programa Parques do Brasil e Programa de Desenvolvimento do Ecoturismo na Amazônia Legal (PROECOTUR Amazônia), de 1990, considerados uma nova variante, o chamado Turismo Verde. Além disso, houve o Programa Nacional de Municipalização do Turismo (PNMT), de 1994, 
atribuindo aos municípios o papel de organizar a oferta turística municipal e realizar inventários do potencial turístico (CANDIOTTO \& BONETTI, 2015).

No Rio de Janeiro, impulsionados pela ECO-92, realizada entre os dias 3 a 14 de junho de 1992, há uma abordagem crescente acerca das questões ambientais, em grande parte incentivada pela mídia nacional, o que acaba por chamar a atenção para esse novo nicho: o Ecoturismo. Logo, o ecoturismo acaba por despertar um debate da sociedade e do ramo empresarial, chamando a atenção para esse turismo junto a natureza, até então, pouco valorizado (ABETA, 2009).

A Rio 92 fez o quê? Trouxe um respaldo, trouxe uma organização para desenvolver o turismo ecológico." "Antes os caras estavam espalhados em cada canto do Brasil. Em 92, se começa a falar de ecoturismo, cria-se essa mobilização em torno do tema Eco 92. O mundo parou para discutir o meio ambiente. Se gerou uma demanda de mercado nas pessoas de conhecerem esse ambiente natural que tanto se falava que estava em extinção, que estava em perigo. Junto com a história do estilo de vida mais saudável, do início da preocupação da nossa sociedade com a natureza... (ABETA, 2009).

Em Bonito, o TA começou de forma organizada em 1993, através do $1^{\circ}$ Curso de Formação de Guias de Turismo Especializados em Atrativos Naturais organizado e promovido pela EMBRATUR, SENAC, SEBRAE-MS, UFMS, Prefeitura de Bonito e Governo do Mato Grosso do Sul. Foi então que surgiram as primeira normas de práticas de visitação ordenada aos locais turísticos da cidade (ABETA, 2009).

Assim como em Bonito, o município de Brotas começou a se organizar para a atividade turística implantando, também em 1993, o Conselho Municipal de Turismo de Brotas, operando inicialmente o boia cross e posteriormente o rafting, pelo qual é popularmente conhecido atualmente (ABETA, 2009).

Os principais marcos do desenvolvimento do TA no Brasil se deu a partir do surgimento e profissionalização de empresas do setor, acompanhado de diversos eventos específicos. A partir de 1997, diversos equipamentos especializados para esse tipo de prática começam a ser produzidos no país, como cordas, polias, capacetes, 
caiaques infláveis, contribuindo, através da facilidade ao acesso desses equipamentos e baixo dos custos dos mesmos, para a expansão desse tipo de turismo (ABETA, 2009).

Certamente, outro fator importante foi a iniciativa privada para a realização da Adventure Sports Fair, a primeira e mais tradicional feira de TA e Ecoturismo do Brasil, repetida anualmente desde sua primeira edição, em 1999. Apesar de não ser uma política pública, a Adventure Sports Fair deu a oportunidade para que os empresários do ramo trocassem experiências em relação à procedimentos de segurança, técnicas, entre outros elementos até então não discutidos, fomentando a troca de ideias e perspectivas para o setor (ABETA, 2009).

Em 2002, com apoio da Embratur e da Secretaria Estadual de São Paulo, a Prefeitura Municipal de Socorro juntamente com o Conselho Municipal de Turismo de Socorro, promoveram uma oficina para a elaboração do Plano para o Desenvolvimento do Turismo de Aventura no Estado de São Paulo, na qual participaram ONG's e representantes de governo e empresas privadas, identificando os limites e potenciais do setor no estado (ABETA, 2009).

A própria criação da Associação Brasileira de Empresas de Ecoturismo e Turismo de Aventura, a ABETA, teve início após uma lista de discussão do Grupo de Empresários de Turismo Aventura (GETA), em Julho de 2003. Acompanhada por um ciclo de Seminários Regionais de Turismo de Aventura no Estado de São Paulo, que tinha por finalidade estimular debates e disseminar informações sobre turismo de aventura e segurança (ABETA, 2009).

Nesse mesmo período, é possível observar um engajamento maior do poder público no TA, num primeiro momento por parte da EMBRATUR, em seguida com a participação do Ministério do Turismo recém-criado (ABETA, 2009). 
Uma das diretrizes necessárias para o desenvolvimento das políticas no ramo foi por meio do Ministério do Turismo, em 2003, viabilizando um projeto com a criação de 24 normas técnicas especialmente para as atividades de TA (OLIVEIRA \& COVOLAN, 2008).

E foi durante o mandato Lula que foi criado o Ministério do Turismo, em 2003, passo importante na concepção de novas políticas em turismo, dando segmento ao Programa de Regionalização do Turismo - Roteiros do Brasil (2006), que continha a proposta de uma política pública de ação, capaz de mudar e sistematizar, de maneira articulada, o processo de planejamento e coordenação de desenvolvimento, desde a esfera local até a nacional, evidenciando e profissionalizando mais o setor (CARVALHO, 2014a).

No mesmo ano, o Ministério do Turismo cria o Plano Nacional do Turismo (PNT), implantado como o instrumento de planejamento que visa desenvolver o Brasil de acordo com as diversidades culturais, regionais e naturais de cada região (LAZARINI \& BARRETO, 2014). Apontado como importante norteador na consolidação de um novo modelo de atividade turística, preconizada pelo Decreto 448/92, considerado o documento oficial mais detalhado no tocante das políticas federais para a atividade relacionada ao turismo (CARVALHO, 2014a).

$\mathrm{Na}$ quinta edição da Adventure Sports Fair, mais precisamente outubro de 2003, houve o primeiro encontro presencial do grupo de empresários, que posteriormente fomentou a criação de grupos específicos mais representativos relativos ao TA, como por exemplo o grupo de Assuntos Jurídicos e Gerenciamento de Risco.

Seguindo a mesma linha de raciocínio, acontece junto ao Ministério do Turismo, em fevereiro de 2004, a primeira reunião do grupo de empresários de TA, 
visando “definir o papel dos empresários dentro da política pública que estava sendo elaborada para o segmento" (ABETA, 2009).

No mais, a criação do Programa Aventura Segura que vem sendo implementado desde 2005 pela ABETA, iniciativa também do Ministério do Turismo, reconhecida internacionalmente e que tem como objetivo uma operação segura e responsável dentro do segmento (ABETA, 2009).

Chegamos finalmente ao governo Dilma Roussef (2011-2016), marcado pela priorização da infraestrutura turística voltada aos Megaeventos Esportivos, como a Copa do Mundo de 2014 e as Olimpíadas de 2016. Associando a infraestrutura urbana ao trabalho do Ministério do Turismo de aperfeiçoamento de recursos humanos por meio do Plano de Aceleração do Crescimento (PAC), Plano Cores do Brasil (marketing nacional) e Plano Aquarela (marketing internacional), tudo isso atrelado ao antigo plano de desenvolvimento (LAZARINI \& BARRETO, 2014), sem dar grande destaque ao segmento de aventura, que beneficiou-se apenas de maneira indireta.

Como destaca o Diagnóstico do turismo de aventura no Brasil: "do ponto de vista político, o Turismo de Aventura conquistou um espaço e firmou-se como segmento econômico, mas precisa urgentemente de consolidar a regulamentação/padronização, a capacitação e a certificação...", o que inclui criar e desenvolver políticas públicas que beneficiem o setor, que ora começou por influência neoliberal, mas, que atualmente tem uma grande vantagem no apoio governamental (ABETA, 2009).

Até o presente momento não foi possível averiguar com profundidade as medidas e políticas públicas em turismo e TA promovidas pelo governo Temer e atual governo Bolsonaro. 


\section{Conclusão}

O que podemos observar é que somente a partir dos anos de 1990, com a influência neoliberal é que o turismo ganha notoriedade e é alavancado através de medidas que buscavam atrair o capital externo, o que inclusive levou o então presidente Collor a trocar papéis da dívida externa por ações turísticas do país. A partir da década de 90, juntamente com a incorporação de um conjunto de medidas neoliberais, que houve abertura econômica ao capital de grandes redes hoteleiras, que por sua vez, começaram a vender o nordeste brasileiro como um produto turístico.

Além disso, houve a reforma tributária e com ela inúmeras privatizações, no qual o setor turístico foi assistido com a parceria público-privada, em que o governo dava medidas que favoreciam o desenvolvimento do setor, porém, se abstraía da responsabilidade direta.

Ainda nessa época, há um enfoque maior no novo termo em ascenção: o Ecoturismo, precursor direto do Turismo de Aventura. O ecoturismo se deu como uma ramificação do mercado turístico que se aproveitou da demanda e ofereceu um novo produto, nesse sentido a cidade de Bonito (MT) foi a pioneira.

O governo Collor instaurou também programas como o Plantur e o Prodetur$\mathrm{NE}$, ambos contavam com a parceria federal e de empresas privadas, um forte indicativo de reflexo neoliberal.

Durante o mandato Itamar Franco e FHC, houveram políticas mais discretas no sentido neoliberal, com a criação dos programas de ecoturismo o Brasil continuou a ser vendido como um produto diferenciado de "selva". O PNMT e o Conselho Nacional de Turismo conseguiram abranger parte das regiões que até então haviam sido negligenciadas. 
Concomitantemente, Brotas cria o Conselho Municipal de Turismo, sendo acompanhada por diversos outros municípios, fortalecendo não só o ecoturismo, mas, dando corpo à sua variável mais recente: o TA.

Devido a popularização do TA, outras cidades começaram a desenvolver seus produtos relacionados, como o município de Socorro (SP), por exemplo. A medida que foram sendo divulgados e conhecidos, esse ramo turístico foi também ganhando suporte da ABETA, a Associação Brasileira dos Empresários de Turismo de Aventura, que começou a fomentar cursos e normas para a profissionalização para o setor.

O surgimento do TA pode ter sido a partir de políticas federais, entretanto, o crescimento e fortalecimento desse nicho se deu principalmente pela exploração desse modelo turístico pelas empresas privadas do setor.

Por sua vez, a criação do MTur, em 2003, deu um salto nos macroprogramas que atingiram os destinos turísticos de aventura. Ainda sob as asas do Plano de Aceleração do Crescimento, houve a destinação de recursos para o setor turístico como um todo, mas, que começaram a se voltar para a infraestrutura de grandes cidades, que mais tarde receberiam os Mega Eventos esportivos.

E mesmo o governo do PT voltando mais o olhar a inclusão das regiões turísticas e diminuição das desigualdades através desse mercado, em nenhum momento o turismo no Brasil deixa de ter influência neoliberal, uma vez que o governo Lula, apesar de se autodeclarar como neodesenvolvimentista, nunca conseguiu romper completamente com o ideário neoliberal, que ainda hoje permeia o país, sobretudo porque as ideias neodesenvolvimentistas não foram suficientemente capazes de desmantelar a coalizão política que fomenta o parecer neoliberal no país. 
Desde então, o Ecoturismo e o TA vêm sendo deixados a parte, inclusive em programas de marketing nacional e internacional (como o Plano Cores do Brasil e Plano Aquarela), destacando-se através de iniciativas privadas como a Adventure Sports Fair, que atrai centenas de pessoas todos os anos.

O que não podemos deixar de notar é essa estreita relação do neoliberalismo e sua influência no Brasil na construção das principais políticas públicas para o setor turístico, e como esse cenário favoreceu o surgimento do TA. Apesar de ter começado por influência neoliberal, a criação e desenvolvimento das políticas públicas em todo o ramo turístico beneficiam esse setor ainda nos dias atuais.

Devemos, portanto, retomar sua relevância e notoriedade por se tratar de uma chave econômica que dá acesso não somente a geração de empregos através de toda a extensão da cadeia prestadora de serviços, mas, como um artefato de geração de renda através de um produto inesgotável, desde que atrelado à sustentabilidade, ou seja, trata-se de uma fonte infindável de trabalho e renda desde que numa gestão responsável, tratando o Brasil como um destino excepcional e diversificado através de seus próprios recursos naturais.

\section{REFERÊNCIAS}

ABETA. Associação Brasileira das Empresas de Ecoturismo e Turismo de Aventura. Diagnóstico do turismo de aventura no Brasil / ABETA e Ministério do Turismo. Belo Horizonte, 2009.

ALVES, Marília da Silva; et al. Normalização do Ecoturismo e Turismo de Aventura no Brasil. Revista Brasileira de Ecoturismo, v.9, n.3, p.433-444. São Paulo, 2016.

ANDERSON, Perry. Pós-neoliberalismo: as políticas sociais e o Estado democrático: Paz e Terra. Balanço do Neoliberalismo, 1995.

BOITO, Armando. Relações de classe na nova fase do neoliberalismo brasileiro. Sujetos sociales y nuevas formas de protesta en la historia reciente de América Latina. CLACSO, Consejo Latinoamericano de Ciencias Sociales. Buenos Aires, 2006. 
BORGES, Carlos; AREIAS, Keni. As políticas públicas de lazer na mediação entre estado e sociedade: possibilidades e limitações. Rev. Bras. Ciênc. Esporte, v. 33, n. 3, p. 573-588. Florianópolis, 2011.

BRASIL, Hildemar Silva; PLANELLO, Priscila Bastos. Plano Nacional de Turismo (2003-2006): Considerações e críticas. Universidade de São Paulo. Disponível em: http://www.ucs.br/site/midia/arquivos/43-plano-nacional.pdf. Acesso em: $10 \mathrm{abr}$. 2019.

BRASIL, Ministério do Turismo. Segmentação do Turismo: Marcos Conceituais. Brasília: Ministério do Turismo, 2006.

BURSZTYN, Ivan. A influência do ideário neoliberal na formulação de políticas públicas de turismo no Brasil. Caderno Virtual de Turismo, vol. 3, núm. 4, p. 7-12. Universidade Federal do Rio de Janeiro. Rio de Janeiro, 2003.

CANDIOTTO, Luciano; BONETTI, Lucas. Trajetória das políticas públicas de turismo no Brasil. UNIOESTE, campus de Francisco Beltrão, v. 8, n. 19. Paraná, 2015 .

CARVALHO, Clébia R. As políticas públicas de (re)ordenamento do turismo no brasil e suas repercussões para a região nordeste: novas ações do governo estadual baiano. Revista Geografia em Atos. Revista Geografia em Atos, n. 14, v.1, p. 48-63. Presidente Prudente, 2014a.

CARVALHO, Fabíola Cristina. Análise das influências internacionais sobre as políticas públicas de turismo no Brasil. CONGRESO LATINOAMERICANO DE INVESTIGACIÓN TURÍSTICA NEUQUÉN, 6. Anais... Neuquém, 2014 b.

CARVALHO, Gisélia Lima. Perspectiva histórico-institucional da política nacional de turismo no brasil (1934-2014). Mercator, Fortaleza, v. 15, n.1, p. 87-99, jan./mar., 2016.

CÁSSARO, Elizandro Ricardo. Atividades de aventura: aproximações preliminares na rede municipal de ensino de Maringá. Monografia. Curso de Pós-Graduação Especialização em Educação Física na Educação Básica, Universidade Estadual de Londrina, 2011.

FILGUEIRAS, Luiz. O neoliberalismo no Brasil: estrutura, dinâmica e ajuste do modelo econômico. Neoliberalismo y sectores dominantes. Tendencias globales y experiencias nacionales. CLACSO, Consejo Latinoamericano de Ciencias Sociales. Buenos Aires, 2006.

GALDINO, Letícia Cristina Fernandes; COSTA, Michele Leandro. Análise das principais políticas públicas de turismo no Brasil, da década de 1990 à atualidade. Observatório de Inovação do Turismo - Revista Acadêmica, v. 6, n. 4, Rio de Janeiro, Setembro de 2011.

GANEM, Angela. Adam Smith e a explicação do mercado como ordem social: uma abordagem histórico-filosófica. Universidade Federal Fluminense. Niterói, 2000. 
GUTIERREZ, Gustavo. O lazer no Brasil: do nacional-desenvolvimentismo à globalização. Conexões, v. 3, n. 1. Campinas, 2005.

HOLANDA, Francisco. Do liberalismo ao neoliberalismo: o itinerário de uma cosmovisão impenitente. 2. ed. Porto Alegre, 2001.

LAZARINI, Ricardo; BARRETO, Margarita. Políticas Públicas no Brasil para um Turismo Responsável. Revista Turismo Visão e Ação - Eletrônica, Vol. 16 - n. 1. 2014.

MULLER, Pierre e SUREL, Yves. O que é política pública? Do Livro L'analyse des politiques publicques, p.10-32. Paris, 1998.

OLIVEIRA, Sérgio Domingos; COVOLAN, Antônio Carlos. A Certificação do Turismo de Aventura no Brasil e o papel das Universidades no contexto da operação segura e responsável. SEMINÁRIO DE PESQUISA EM TURISMO DO MERCOSUL, 5, 2008. - SeminTUR Turismo: Inovações da Pesquisa na América Latina Universidade de Caxias do Sul - UCS. Anais... Caxias do Sul, RS, 27 e 28 de Junho de 2008.

PIANHERI, Marília Viveiros. O liberalismo e sua decadência. São Paulo, 2014. Disponível em: http://mapianheri.jusbrasil.com.br/artigos/135223265/o-liberalismo-esua-decadencia Acesso em: 22 nov. 2017.

SILVA, Fabiana dos Santos; COSTA, Sarany Rodrigues; CARVALHO, Conceição de Maria Belfort. Políticas públicas de turismo no brasil: estratégias para administração da atividade no país. SIMPÓSIO DE EXCELÊNCIA EM GESTÃO E TECNOLOGIA, 10, Outubro de 2013. Anais... 2013.

SILVA, Heloisa C. M. Deterioração dos termos de intercâmbio, substituição de importações, industrialização e substituição de exportações: a política de comércio exterior brasileira de 1945 a 1979. Revista brasileira polít. int., v.46 n.1. Brasília, 2003.

SMITH, Adam. A mão invisível. (obra extraída do livro: A Riqueza das Nações, de Adam Smith, 1776). Penguin \& Companhia das Letras. Pág. 03-45. 2013.

TELES, Reinaldo, et al. Turismo e política externa brasileira: de Vargas a Dilma. Coleção Comunicação e Políticas Públicas, v. 20, Cap. 1, e de 7 a 9. Universidade Federal de Roraima, 2016.

\section{Endereço das Autoras:}

Rosane Camila de Godoi

Faculdade de Educação Física da Unicamp

Av. Érico Veríssimo 701 - Cidade Universitária Zeferino Vaz

Campinas - SP - 13.083-851

Endereço Eletrônico: r118640@dac.unicamp.br 


\section{Silvia Cristina Franco Amaral}

Faculdade de Educação Física da Unicamp

Av. Érico Veríssimo 701 - Cidade Universitária Zeferino Vaz

Campinas - SP - 13.083-851

Endereço Eletrônico: scfa007@gmail.com 